\title{
Avaliação do desempenho de canal gramado na remoção de material suspenso em escoamento superficial pluvial
}

\author{
Performance of natural channel on removing suspended matter from runoff \\ Rodrigo Braga Moruzzi', Mayara Felipe ${ }^{2}$, \\ Ademir Paceli Barbassa ${ }^{3}$, Daniel de Lima Nascimento Sírio ${ }^{4}$
}

\begin{abstract}
口
\section{RESUMO}

Neste trabalho, buscou-se avaliar o desempenho de canal gramado na remoção de material suspenso presente em escoamento superficial em unidade construída em escala real. Para tal, foram investigadas diferentes concentrações iniciais de material particulado, o qual foi descarregado por meio de chuvas simuladas em canal de $100 \mathrm{~m}$ de extensão e declividade de $2 \%$. As medidas de material particulado foram feitas mediante a análise de sólidos suspensos totais (SST) em diferentes posições ao longo do canal. Os hidrogramas de descarregamento e as lâminas de água no canal foram monitorados durante a passagem da onda de cheia. Avaliaram-se as frações removidas para cada evento isolado e também em conjunto, por intermédio da interpolação por krigagem. Remoções da ordem de 50\% foram obtidas para a posição de $50 \mathrm{~m}$ do canal gramado e de $70 \%$ para a posição de $80 \mathrm{~m}$. Os resultados mostraram que a remoção de material particulado é fortemente dependente da extensão do canal e que os aspectos dinâmicos decorrentes da passagem da onda de cheia influenciam no processo.
\end{abstract}

Palavras-chave: drenagem urbana; poluição difusa; chuva simulada.

\begin{abstract}
In this study, the performance of a natural channel in removing particulate matter from runoff was evaluate. For this purpose, different initial concentrations of particles, which were discharged by means of simulated $100 \mathrm{~m}$ in length and slope of $2 \%$ channel rains, were investigated. The measurements of particulate matter were made by means of total suspended solids (TSS) at different positions along the channel. Hydrograph and water levels in the canal during the passage of the flood wave were monitored. The removed fractions for each one of the isolated essays and also in a combined way were evaluated, by applying kriging interpolation. Removals around 50\% were obtained for the channel position of $50 \mathrm{~m}$ and $70 \%$ for channel position of $80 \mathrm{~m}$. The results indicated that the removal of particulate material is strongly dependent on the extension of the channel and the dynamic aspects arising from the passage of the flood wave influence in the process.
\end{abstract}

Keywords: urban drainage; diffuse pollution; simulated rain.

\section{INTRODUÇÃO}

As inundações urbanas, as quais decorrem do escoamento superficial direto (ESD) das precipitações excedentes, consistem num problema recorrente em diversos municípios brasileiros. Como forma de diminuir os efeitos gerados pelos excessos escoados, podem ser empregadas técnicas de detenção e retenção difusas na bacia hidrográfica. Tais técnicas compensatórias, também conhecidas como sistema alternativo de drenagem, podem ser aplicadas em nível de lote ou loteamento.
Esse sistema alternativo visa diminuir a quantidade de água nas galerias e nos rios durante o pico das chuvas por meio da infiltração da água no solo, da diminuição da velocidade de escoamento e do aumento da taxa de evapotranspiração, possibilitando a proteção da qualidade da água e a implantação de paisagens ambientalmente agradáveis. Essas tecnologias também são vistas como alternativas por considerarem os impactos da urbanização de modo global, tomando a bacia hidrográfica como referência. Ou seja, a

'Doutor em Engenharia Civil, pela Escola de Engenharia de São Carlos (EESC) da Universidade de São Paulo (USP). Professor adjunto III do Instituto de Geociências e Ciências Exatas (IGCE), da Universidade Estadual Paulista “Júlio de Mesquita Filho" (Unesp) - Campus Rio Claro, Departamento de Planejamento Territorial e Geoprocessamento (Deplan), Laboratório de Tratamento e Reuso de Água e Efluentes (Latare) - Rio Claro (SP), Brasil.

2Doutoranda em Engenharia Hidráulica e Saneamento da EESC-USP - Rio Claro (SP), Brasil.

${ }^{3}$ Professor titular da Universidade Federal de São Carlos (UFSCar) - São Carlos (SP), Brasil.

${ }^{4}$ Doutorando em Engenharia Urbana da UFSCar - São Carlos (SP), Brasil. Professor do curso de Engenharia Civil do Departamento de Hidráulica e Saneamento, do Centro de Ciência e Tecnologia da Universidade Estadual do Maranhão (Uema) - São Luís (MA), Brasil.

Endereço para correspondência: Rodrigo Braga Moruzzi - Avenida 24A, 1.515 - Vila Indaia - 13506-900 - Rio Claro (SP), Brasil - E-mail: rmoruzzi@rc.unesp.br Recebido: 24/10/14 - Aceito: 28/06/16 - Reg. ABES: 142045 
compensação dá-se pelo controle da precipitação excedente, com o intuito de evitar sua transferência rápida para as áreas à jusante (BAPTISTA et al., 2011).

Por outro lado, sabe-se que a poluição do escoamento superficial direto pode ser elevada, em função das variações de poluentes e concentrações nele carreados, podendo-se afirmar que a maioria dos poluentes encontrados é material particulado de forma orgânica e inorgânica (TUCCI, 2005) e que a qualidade da água, nesse caso, varia muito no espaço e no tempo. Nesse sentido, a redução da poluição difusa por intermédio da separação dos materiais particulados presentes no escoamento superficial direto constitui um benefício complementar a essas técnicas, no entanto pouco se sabe a respeito da extensão da remoção de poluentes em técnicas compensatórias em drenagem urbana, bem como dos fenômenos de separação sólido/líquido predominantes.

Dessa maneira, este trabalho buscou avaliar o desempenho de um canal gramado na remoção de material particulado presente no escoamento superficial direto. Para tal, o canal gramado em substituição a canaleta de infiltração foi construído no campus da Universidade Federal de São Carlos (UFSCar) e visou coletar as águas pluviais escoadas em superfície dos prédios do Departamento de Medicina II e do de Gerontologia, o qual conduz o escoamento até o plano.

Apresenta-se a seguir uma breve revisão sobre o assunto.

\section{Técnicas alternativas em drenagem urbana}

$\mathrm{O}$ conceito higienista de manejo preconiza o afastamento rápido das águas pluviais por meio de rede de condutos e predominou no mundo inteiro até a segunda metade do século XX. Por volta dos anos 1970 se iniciaram as tecnologias alternativas de drenagem urbana. Nessa nova visão, adotaram-se a retenção e a detenção das águas pluviais em contraposição à aceleração do escoamento, e reconheceu-se a poluição do esgoto pluvial. Tais tecnologias foram denominadas de técnicas compensatórias ou best management practices (BMP) e visam controlar as enchentes e remover poluentes. $\mathrm{O}$ controle das vazões excedentes, ou volumes, pode ocorrer de forma centralizada, como as bacias de detenção ou retenção, ou de forma descentralizada, como pavimentos permeáveis, superfícies, poços, planos, trincheiras e valas de infiltração, reservatórios. Essa nova concepção teve mais impulso na década de 1980 até os dias atuais e ganha força na medida do avanço das pesquisas e do relato de experiências bem-sucedidas (SILVEIRA, 2002).

Na década de 1990 surgiu uma nova abordagem de gestão sustentável de drenagem, conhecida como desenvolvimento de baixo impacto (Low Impact Development - LID), o qual busca compatibilizar o leiaute das estruturas, atendendo à paisagem e satisfazendo às exigências estéticas sem prejuizos sanitários ou ambientais (PERSON et al., 1999).
O LID pode ser descrito, no que se refere às águas pluviais, como um conjunto de técnicas urbanísticas e de drenagem que têm como propósito manter o ciclo natural das águas, no período anterior à urbanização, mediante estímulos químicos, físicos e biológicos (TUCCI, 2005).

Dessa maneira, busca-se o escoamento das águas em condições adequadas ao meio ambiente, ou seja, a água infiltra, filtra, armazena, evapora controlando o escoamento junto à sua fonte. Além disso, mostra-se como uma alternativa sustentável para as questões que atualmente cercam a drenagem urbana, de modo especial por mitigar os impactos do sistema e os gastos com o tratamento das águas.

Estrategicamente, seu objetivo de conservação dos processos hidrológicos e dos recursos naturais estimula a prevenção da poluição do solo e das águas.

O LID pressupõe um planejamento de ocupação do espaço urbano que amenize o escoamento superficial; mantenha os canais de drenagem; conserve os ecossistemas e recursos naturais, buscando diminuir os espaços impermeabilizados das superfícies; controle a poluição da água pluvial e reduza as fontes de contaminação; insira na drenagem dispositivos hidráulicos que aumentem o tempo de concentração das águas; e promova de alguma maneira atividades de proteção do meio ambiente e programas de educação ambiental no intuito de atualizar ações voltadas para a drenagem fluvial (GEORGE'S COUNTY, 1999).

\section{Qualidade da água do escoamento superficial}

As alterações do equilíbrio do microambiente estão diretamente relacionadas com a modificação da cobertura vegetal por construções e ruas pavimentadas, o que por consequência interfere no processo de infiltração do solo, bem como no sistema de águas pluviais urbanas, e no aumento da radiação nas superfícies por intermédio do ciclo térmico (GUTIERREZ, 2011).

Em alguns países os estudos referentes à poluição gerada pelo escoamento superficial em meio urbano ocorrem há longo tempo. Nos Estados Unidos, em meados da década de 1960, a Agência de Proteção Ambiental (EPA) identificou que as cargas associadas às descargas ou vazões provenientes de cheias urbanas representavam grandes fontes de poluição dos corpos hídricos (EPA, 1999). Em 1972, o Programa Nacional de Escoamentos Urbanos (NURP, do termo em inglês Nationwide Urban Runoff Program) foi estabelecido, com a meta principal de promover a investigação da poluição das águas no ambiente urbano. Os resultados registrados no tratamento dos efluentes sanitários de algumas cidades americanas, apresentados no relatório final do NURP, confirmaram que as fontes de poluição difusa foram identificadas como as maiores causadoras de degradação da qualidade dos escoamentos superficiais (EPA, 1999).

Segundo Urbonas e Stahre (1993), a poluição difusa de origem pluvial inicia-se com o arraste dos poluentes atmosféricos pela chuva e termina no escoamento superficial, sendo este o responsável direto 
pelo transporte dos poluentes dispostos sobre a superfície das áreas urbanas até o lançamento no corpo receptor. Portanto, nota-se a relação direta entre a poluição difusa e o ciclo hidrológico.

Do ponto de vista da qualidade das águas pluviais, os impactos da urbanização são também significativos pela carga de poluição dessas águas. Até há pouco tempo consideradas aparentemente limpas, tais águas mostram-se superiores às cargas poluentes dos efluentes sanitários (BAPTISTA et al., 2011).

A magnitude do impacto causado pela drenagem urbana ao chegar aos corpos receptores depende, por exemplo, do estado do afluente antes do lançamento, da sua capacidade assimilativa, da concentração de substâncias tóxicas aportadas, do uso do solo na bacia e do tipo e da quantidade de poluentes carreados. Os impactos podem ser divididos em seis grandes categorias: alterações estéticas, depósitos de sedimentos, depleção da concentração de oxigênio dissolvido, contaminação por organismos patogênicos, eutrofização e danos por conta da presença de tóxicos (CAMPBELL et al., 2004; PORTO, 1995).

De acordo com Humbel et al. (2004), com a caracterização dos escoamentos superficiais urbanos, notou-se que os poluentes (demanda química de oxigênio - DQO, demanda biológica de oxigênio - DBO5, hidrocarbonetos, metais pesados, entre outros) são principalmente fixados sobre os materiais em suspensão.

Os sistemas tradicionais de drenagem estão se tornando insuficientes e caros para gerenciar os escoamentos gerados pelas águas pluviais, sendo necessário intervir em todos os níveis do ciclo urbano da água para reduzir o volume do escoamento superficial e sua poluição. Portanto, as BMPs surgiram como um meio de controlar a poluição difusa (SILVA et al., 2009).

Sabendo-se que os sólidos suspensos totais (SST) transportam a maior parte dos poluentes encontrados no escoamento superficial urbano, Li e Pyatt (2004) analisaram a eficiência de uma bacia de detenção de grande porte, com período de detenção de projeto de 24 horas, em Lion, na França. Os resultados mostraram que um dispositivo desse porte apresenta eficiência média bem elevada, em torno de $90 \%$. Os autores atribuem esse bom desempenho à floculação dos sedimentos finos. Parkinson e Mark (2008) afirmam que nos países em desenvolvimento o uso dessas técnicas, especialmente nos canais gramados, é crescente e que em muitas vezes pode estar aliado a outras estruturas de drenagem, tais como trincheiras e sistemas de infiltração. No entanto, continuam os autores, essas técnicas têm potencial de ser aplicadas em todo o mundo, com efeito, no controle do escoamento superficial e pela boa performance de remoção de particulados e poluentes.

Para Blick et al. (2004), o transporte de água em canal gramado tende a aumentar a rugosidade da superfície ao longo do canal, diminuindo consideravelmente a velocidade de escoamento. Em consequência, favorece a sedimentação de particulados. Ademais, os canais gramados podem promover parte do tratamento do escoamento, em função da diminuição da concentração de poluentes por metro de trajeto. Para tanto, as condições específicas do local, tais como inclinação, tipo de solo, área de drenagem, e as restrições do local devem ser consideradas no projeto de um canal gramado (BLICK et al., 2004).

Em experimentos de campo realizados por Gharabaghi et al. (2000) em faixas gramadas, puderam-se observar as eficiências médias entre 50 e $98 \%$ para 2,44; 4,88; 9,76; e 19,52 m de extensão na remoção de sedimentos. Os primeiros cinco metros dessas faixas de infiltração são muito eficazes na remoção de sedimentos suspensos. Mais de $95 \%$ dos agregados maiores que $40 \mu \mathrm{m}$ de diâmetro podem ser capturados nos primeiros 5 metros desse filtro.

O conhecimento das condições de escoamento é fundamental para o entendimento da remoção de material particulado, e existem muitas questões ainda não respondidas. Estudos conduzidos por Lima e Abrantes (2014) mostram a variação do perfil de velocidade em escoamento com baixa lâmina empregando termografia de infravermelho e comparam resultados com ensaios tradicionais de estímulo e resposta, demonstrando a aplicabilidade da técnica e abrindo novas possibilidades de investigação.

Nesse sentido, o presente estudo é capaz de auxiliar na compreensão do desempenho de canal gramado sobre regime não permanente e iniciar a discussão acerca de sua relação com a variação espaçotemporal das lâminas de água resultantes da passagem do escoamento superficial direto.

\section{METODOLOGIA}

O sistema investigado foi construído em escala real no campus da UFSCar, na cidade de São Carlos (SP).

O canal gramado foi implantado em uma microbacia experimental, localizada na zona norte da universidade, com a finalidade de manejo de água pluvial dos prédios dos departamentos de Medicina II e de Gerontologia, como ilustrado na Figura 1.

O dispositivo estudado tem $100 \mathrm{~m}$ de extensão e $2 \%$ de declividade. A água pluvial proveniente do telhado do prédio do Departamento de Medicina II é drenada pelas instalações hidráulicas prediais e depois conduzida para o canal gramado. Já a água precipitada no prédio do Departamento de Gerontologia é conduzida por um canal gramado secundário, desembocando no canal gramado principal, objeto do estudo.

\section{Simulação de chuva por meio do uso de reservatório}

As simulações de chuva foram empregadas visando manter o hidrograma de entrada e a concentração de material particulado constantes no afluente ao canal gramado.

Simularam-se cinco descargas de sólidos com ensaios em duplicata para cada evento, alterando a concentração do material particulado inicial e 
mantendo-se fixo o hidrograma de entrada. Para tal finalidade, foi utilizado um reservatório de $5 \mathrm{~m}^{3}$ de volume útil. O nível no interior do reservatório foi mantido constante para cada condição inicial dos ensaios, correspondente à lâmina de $1,34 \mathrm{~m}$, a qual se refere ao volume de $4,2 \mathrm{~m}^{3}$. Na saída do reservatório se instalou um tubo de policloreto de vinila (PCV) de $75 \mathrm{~mm}$, conectado a um registro esfera, e este a um cotovelo de $90^{\circ}$.

A variação do nível do reservatório foi monitorada por meio do medidor de nível modelo OTT Orpheus Mini. Para cada nível, calculou-se a vazão equivalente, de modo a construir o hidrograma de descarregamento típico da chuva simulada, conforme Figura 2.
As lâminas de água no canal gramado após o descarregamento foram medidas em diferentes posições, por meio de réguas instaladas nas seguintes porções, de montante para jusante: 0,$0 ; 15,3 ; 30,7 ; 55,5$; 70,3; e 93,2 m.

Foram determinadas as vazões específicas com base na área, calculadas com a lâmina média medida ao longo do comprimento do canal, e na lâmina no ponto de descarregamento do reservatório. Para isso, empregaram-se as Equações 1 e 2.

$q_{\bar{e}}=\frac{q m e ́ d}{L e}$

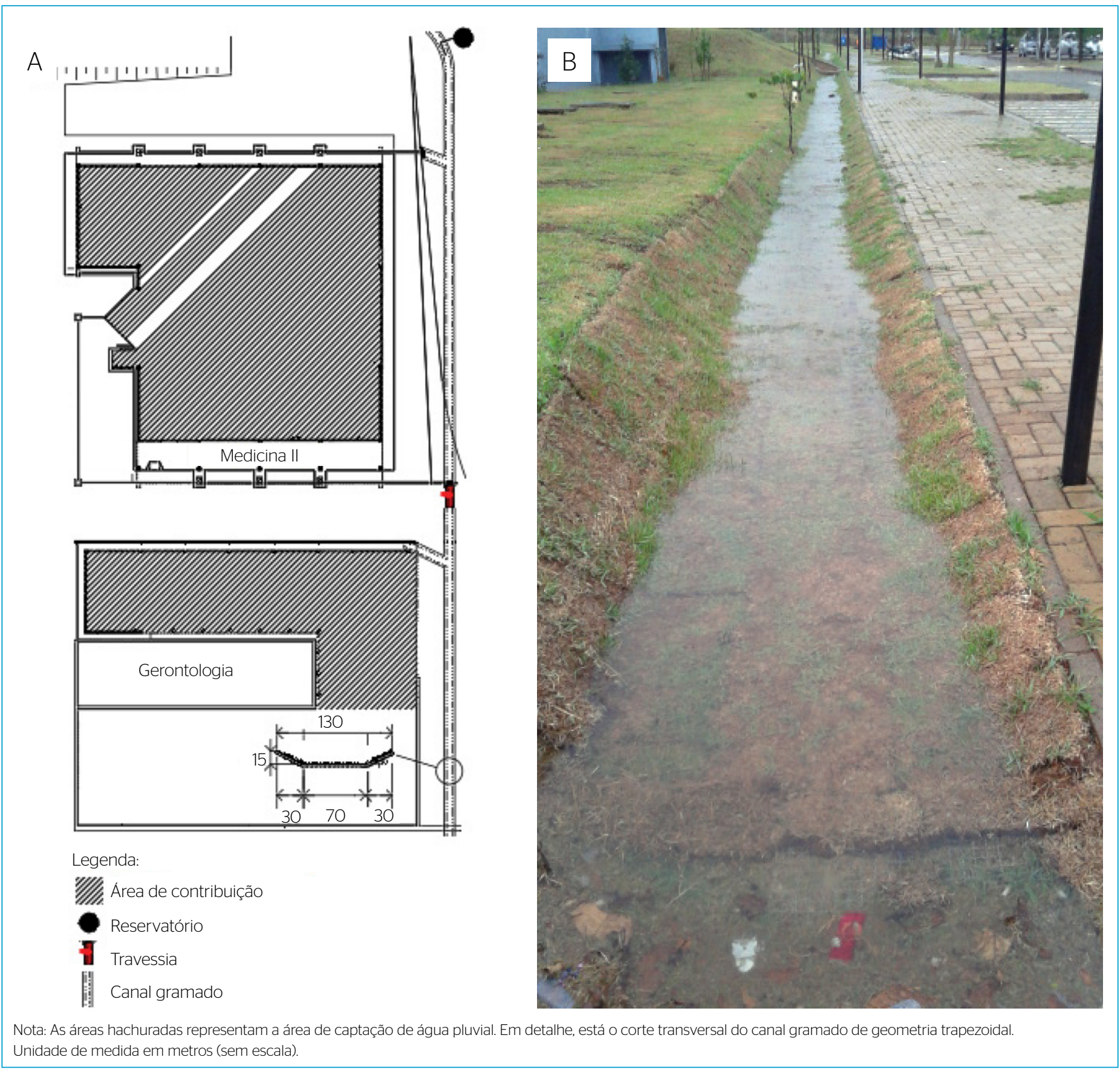

Figura 1 - (A) Vista em planta da área drenada para o canal gramado localizada ao lado dos prédios dos departamentos de Medicina Il e Gerontologia; e (B) fotografia do canal grama de jusante para montante. 
$q_{m}=\frac{q m a ́ x}{L m}$

Em que:

$q_{\overline{\mathrm{e}}}=$ vazão específica referente à lâmina d'água média do canal $\left(\mathrm{m}^{3} \cdot \mathrm{s}^{-1} \cdot \mathrm{m}^{-2}\right)$; Qméd = valor médio das vazões medidas do hidrograma $\left(\mathrm{m}^{3} \cdot \mathrm{s}^{-1}\right)$;

$L_{\mathrm{e}}=$ área trapezoidal do canal, considerando a lâmina de água média $\left(\mathrm{m}^{2}\right)$;

$q_{\mathrm{m}}=$ vazão específica referente à lâmina no ponto de descarregamento do reservatório $\left(\mathrm{m}^{3} \cdot \mathrm{s}^{-1} \cdot \mathrm{m}^{-2}\right)$;

Qmáx = valor máximo da vazão medida no hidrograma $\left(\mathrm{m}^{3} \cdot \mathrm{s}^{-1}\right)$;

$L_{\mathrm{m}}=$ área trapezoidal do canal, considerando a lâmina d'água máxima livre $\left(\mathrm{m}^{2}\right)$.

A eficiência (E\%) na remoção de SST foi determinada para diferentes seções ao longo do comprimento do canal, conforme Equação 3.

$E(\%)=1-\left(\frac{N}{N o}\right) \cdot 100$

Em que:

$N=$ turbidez no coletor correspondente a sua posição (UNT);

No $=$ turbidez inicial medida no reservatório após introdução de material particulado (UNT).

\section{Aspectos qualitativos: determinação das cargas poluidoras do escoamento de águas pluviais}

A remoção de material particulado foi avaliada para diferentes posições do canal gramado, com base na introdução de várias concentrações de solo peneirado no reservatório de descarregamento. As posições de amostragem e suas distâncias foram definidas por intermédio

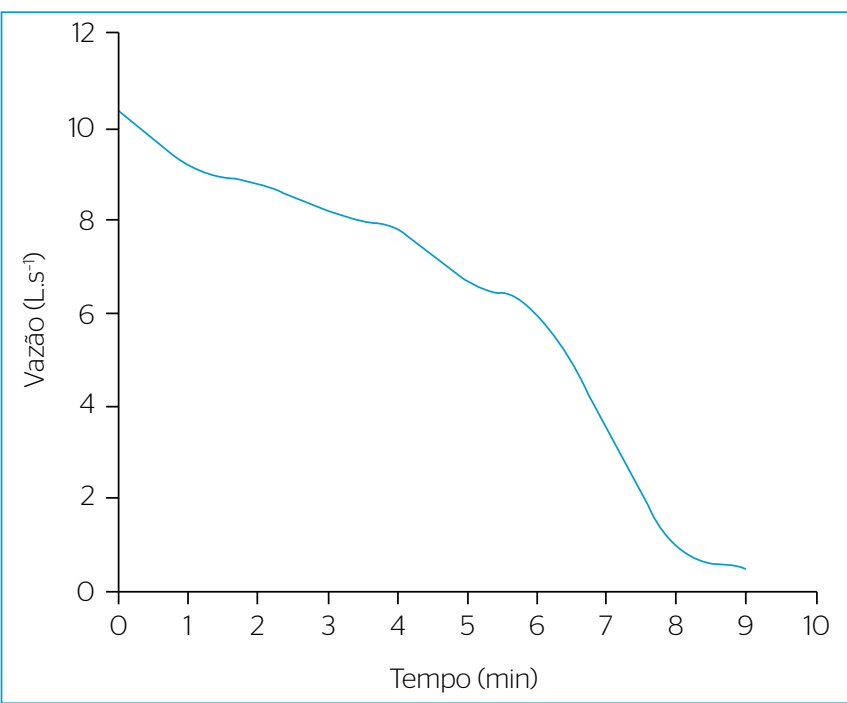

Figura 2 - Hidrograma típico de chuva simulada por meio do descarregamento de reservatório de $5 \mathrm{~m}^{3}$ com tubo curto de $75 \mathrm{~mm}$ de diâmetro nominal medido durante as operações de descarregamento do reservatório. de ensaios preliminares, em que se verificou a necessidade de maior frequência de amostragem nos comprimentos iniciais do canal gramado. Constatou-se que as medições nos primeiros $10 \mathrm{~m}$ são fundamentais para acompanhamento do decaimento e que menores frequências de amostragem podem ser tomadas nos últimos metros do canal gramado. As concentrações investigadas foram: 65; 130; 196; 262; e 327 mg.L.-

O solo utilizado para simulação de material particulado presente na água pluvial foi coletado de uma área próxima ao canal gramado, de modo a representar o material particulado presente na água pluvial. Depois da coleta, o solo foi separado por peneira n. ${ }^{\circ} 200$, com diâmetro equivalente a $0,074 \mathrm{~mm}$, pesado e armazenado em sacos plásticos, para posterior introdução no reservatório de descarregamento.

A concentração residual remanescente de material particulado foi avaliada em diversos pontos por toda a extensão do canal gramado, mediante a instalação de coletores em diferentes posições ao longo do comprimento do canal (Figura 3).

Os coletores, de $206 \mathrm{~mL}$ cada, têm formato cilíndrico e foram montados com tubulação de $50 \mathrm{~mm}$ de PVC, dois caps de $50 \mathrm{~mm}$, com um furo central de diâmetro de $32 \mathrm{~mm}$. Uma esfera de poliestileno de $3 \mathrm{~cm}$ foi introduzida no interior de cada coletor para fechamento da entrada, a qual ocorria por empuxo por conta da variação interna de nível de água. Os coletores foram encapsulados no solo, a fim de evitar interferência de material particulado de fonte externa. Para tal, empregaram-se tubos de PVC de $75 \mathrm{~mm}$ com $11 \mathrm{~cm}$ de comprimento, os quais foram enterrados no solo e vedados com manta de borracha.

Para compatibilizar o tempo de resposta de cada ensaio ao tempo de análise requerido, foi construída uma curva de calibração, a qual relaciona as medidas de SST e turbidez. Assim, para o material particulado introduzido no reservatório, foram avaliadas várias concentrações de SST e sua correspondência com medidas de turbidez, mediante a média de amostragens em triplicata.

Desse modo, a carga poluidora presente na forma de SST pôde ser rapidamente avaliada por meio das medidas de turbidez, as quais se realizaram com auxílio de um turbidímetro de bancada, e os valores expressos em Unidade Nefelométrica de Turbidez (UNT), conforme a American Public Health Association (APHA, 2005).

Os coletores foram distribuídos e instalados ao longo do eixo do canal gramado da seguinte maneira: 10 coletores espaçados de $1 \mathrm{~m}$, seguidos de cinco coletores espaçados em $2 \mathrm{~m}$; seis coletores espaçados de $5 \mathrm{~m}$; e cinco coletores espaçados de $10 \mathrm{~m}$, contados de montante para jusante.

Antes da realização de cada ensaio, o canal gramado foi lavado com água proveniente do poço profundo, descarregada pelo mesmo reservatório empregado nos ensaios. Tal procedimento visou minimizar o efeito do transporte de material particulado depositado em tempo pretérito. 
Os valores de turbidez residual remanescente, bem como eficiências de remoção correspondentes, foram avaliados individualmente e por intermédio das médias das amostras distribuídas nos pontos de coleta. Adicionalmente, construíram-se curvas de ajuste de decaimento e explicitaram-se seus parâmetros correspondentes. Por fim, as eficiências obtidas nos pontos de coleta foram interpoladas em função do comprimento e das concentrações iniciais (Co), por meio da técnica de krigagem aplicada aos dados da vizinhança, obtendo assim curvas de isoeficiência. Para isso, o software Surfer ${ }^{\circledR}$ foi empregado nas interpolações.

$\mathrm{Na}$ Figura 4 é apresentada a vista em planta do canal gramado com indicação da disposição espacial dos coletores.

\section{RESULTADOS}

A relação entre SST e turbidez, construída para o material particulado empregado neste estudo, pode ser verificada na Figura 5. O coeficiente de determinação da reta de ajuste $\left(\mathrm{R}^{2}\right)$ de 0,95 indica boa representação dos valores de SST por meio da turbidez, cujo quociente é 11,69 (mg.L $\left.\mathrm{L}^{-1} \cdot \mathrm{NTU}^{-1}\right)$. Assim, foi possível avaliar a concentração de material particulado por intermédio da medida indireta da turbidez, compatibilizando o tempo de resposta requerido ao tempo de análise das amostras nos diferentes ensaios.

$\mathrm{Na}$ Tabela 1, verifica-se o efeito da passagem da onda de cheia pelo canal, incorrendo em variação espacial e temporal das lâminas d'água medidas. Para efeito de parâmetro de projeto, foram determinadas as lâminas em situações específicas, expressas pala média e pela máxima lâmina detectada no canal gramado. De posse desses valores, foram estimadas as vazões específicas para a condição média $\left(q_{\mathrm{e}}\right)$ e para a condição referente à maior lâmina $\left(q_{\mathrm{m}}\right)$, conforme descrito nas Equações 1 e 2, as quais resultaram nos dados apresentados na Tabela 2. Nessas condições, constataram-se valores de $q_{\mathrm{e}}$ de 0,26 e $q_{\mathrm{m}}$ de $0,20 \mathrm{~m}^{3} \cdot \mathrm{s}^{-1} \cdot \mathrm{m}^{-2}$.

Pela análise da Figura 6, pode-se observar que: em termos médios (temporais e espaciais), viu-se que a lâmina decai do ponto máximo

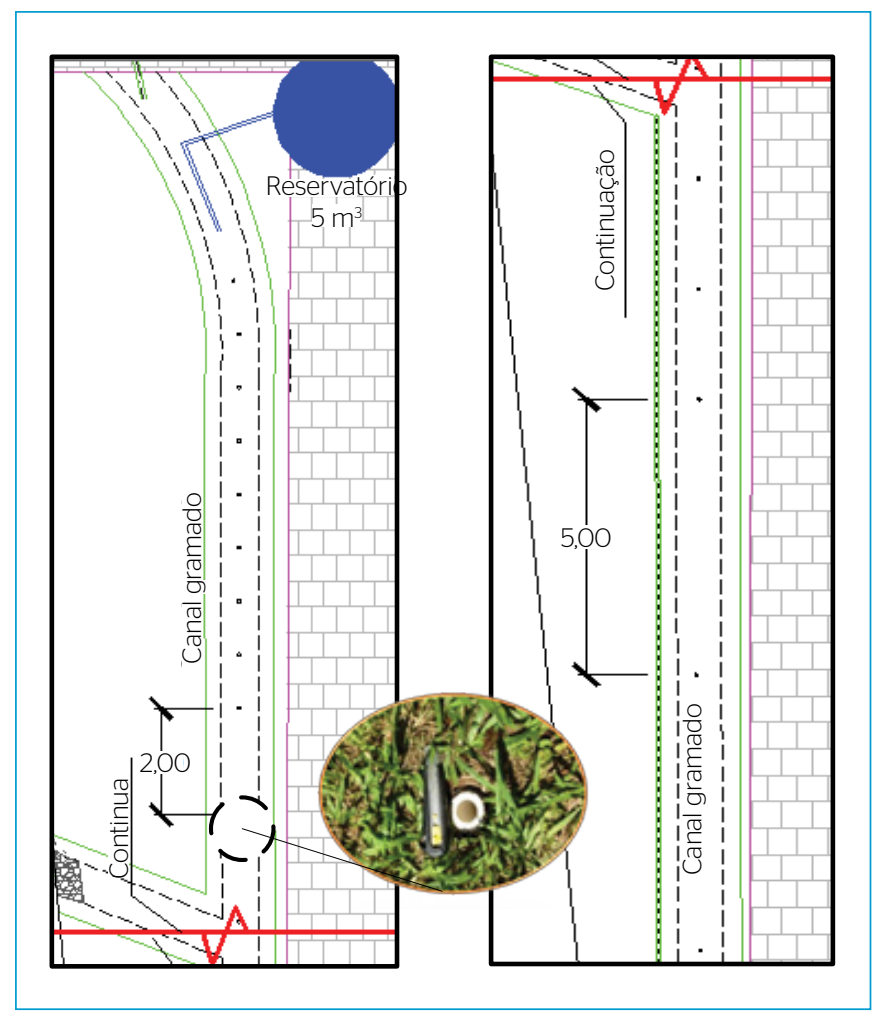

Figura 4 - Vista seccionada em planta do canal gramado com indicação do reservatório para descarregamento e dos coletores espaçados ao longo do comprimento do canal. A vista foi seccionada na posição indicada em vermelho, para facilitar a visualização. Em detalhe, fotografia do coletor ao lado de um objeto de $12 \mathrm{~cm}$. Sem escala.

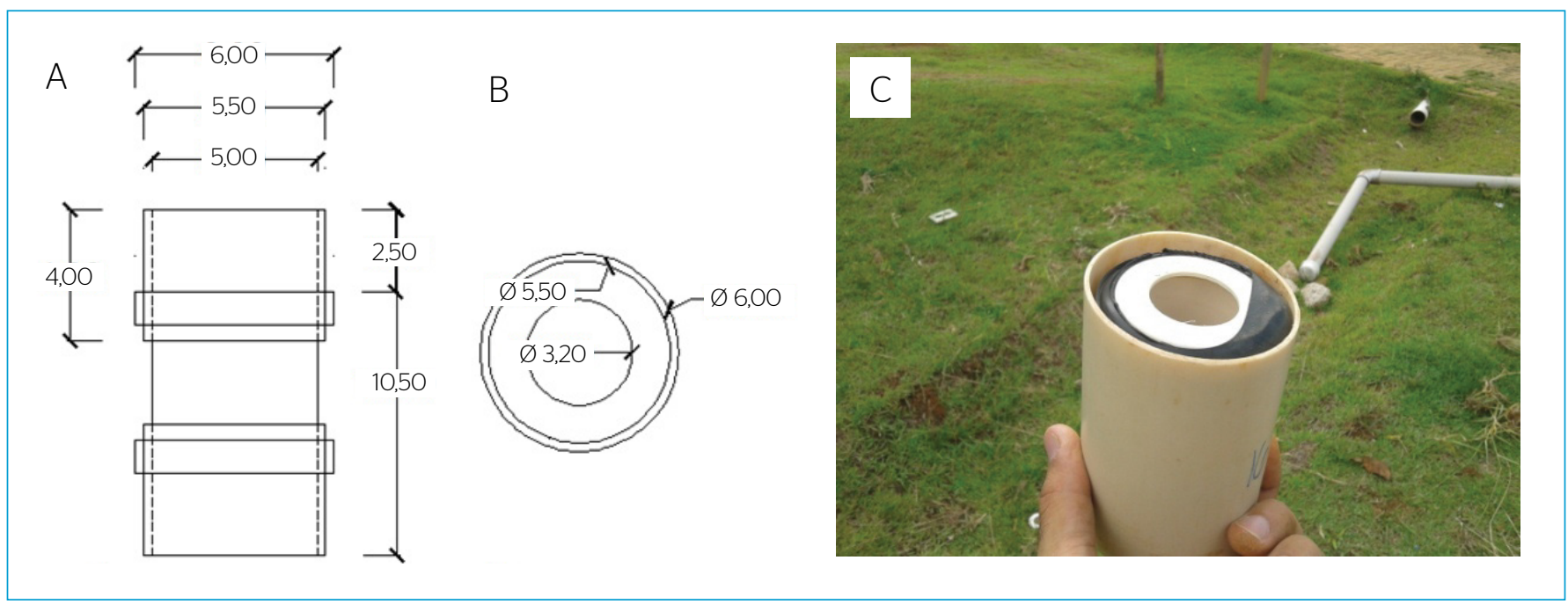

Figura 3 - (A) Vista lateral do coletor de amostra montado com tubo de PVC; (B) vista superior do coletor com abertura superior de $32 \mathrm{~mm}$; $\mathrm{e}$ (C) Coletor de amostra. Sem escala. Medidas em $\mathrm{cm}$. 
à taxa de $2,81 \mathrm{~cm} \cdot \mathrm{m}^{-1}$ do canal, para todos os ensaios realizados. Isso aponta o efeito da passagem da onda de cheia, bem como o efeito da infiltração da água no canal gramado.

Levando em conta somente a média temporal das lâminas, nas diferentes posições do canal, visualizou-se a existência de um pico de nível na posição em torno de $20 \mathrm{~m}$ (variação de $\pm 5 \mathrm{~m}$ ). O mesmo decorreu da passagem da onda de cheia pelo canal gramado.

As considerações descritas são de fundamental importância para a compreensão do fenômeno de remoção de material particulado em técnicas compensatórias dessa natureza, uma vez que a remoção é dependente da ação da força gravitacional sobre a partícula, a qual depende de sua massa e das condições de escoamento presentes. Maiores valores de lâmina d'água podem indicar maiores trajetórias de percurso vertical. Todavia, na análise dinâmica do escoamento, maiores lâminas também sugerem maiores velocidades locais. Assim, a remoção do material particulado, a qual decorre da sua deposição

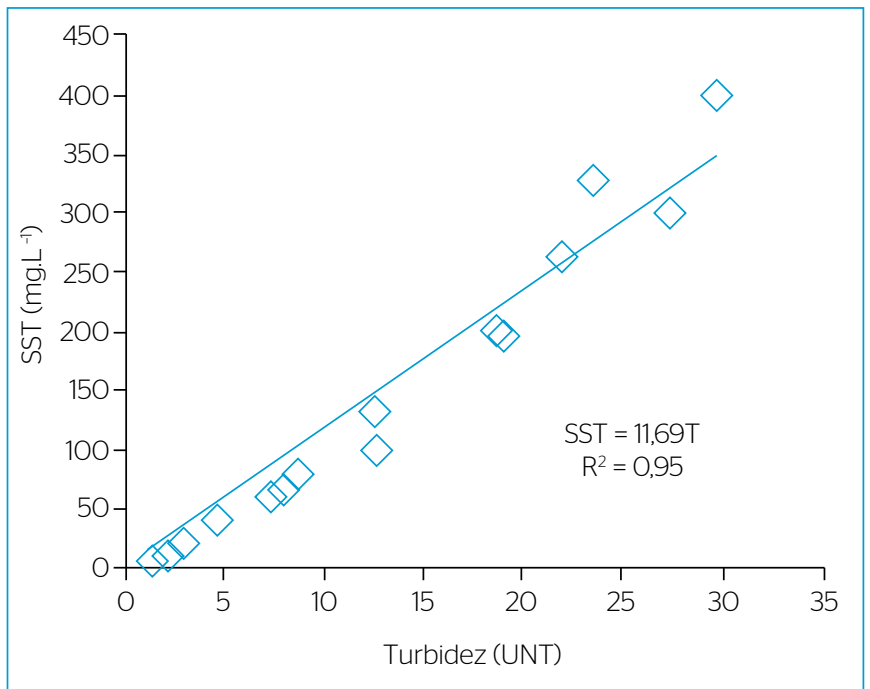

Figura 5 - Relação entre sólidos suspensos totais (SST) e turbidez construída para o material particulado introduzido no reservatório de descarregamento no canal gramado.

Tabela 1 - Valores temporais e espaciais de lâmina d'água medidos no canal durante os ensaios com as chuvas simuladas.

\begin{tabular}{l|c|c|c|c|c|c}
\multirow{2}{*}{$\begin{array}{l}\text { Tempo } \\
(\text { min })\end{array}$} & \multicolumn{7}{|c}{ Comprimento (m) } \\
\cline { 2 - 7 } & $0,0^{*}$ & 15,3 & 30,7 & 55,5 & 70,3 & 93,2 \\
\hline 5 & 6,0 & 6,3 & - & - & - & - \\
\hline 10 & 3,2 & 5,4 & 5,1 & 4,5 & - & - \\
\hline 15 & 1,0 & 2,2 & 5,5 & 4,2 & 3,2 & - \\
\hline 20 & 0,5 & - & 1,0 & 1,3 & 2,2 & 1,5 \\
\hline 25 & - & - & - & 1,0 & 2,0 & 4,1 \\
\hline 30 & - & - & - & - & 1,7 & 1,3 \\
\hline
\end{tabular}

*A posição 0,0 indica o ponto de descarregamento do reservatório, seguindo assim o sentido de montante para jusante; -) não houve lâmina medida. na superfície, depende de diferentes proporções e ordens da lâmina d'água e das velocidades de escoamento locais.

$\mathrm{Na}$ Tabela 3 são apresentados os resultados médios de remoção quanto aos pontos de amostragem, posicionados ao longo do comprimento do canal gramado. Verificou-se que, em termos médios, a remoção nos diferentes pontos tende a piorar com o aumento da concentração inicial.

Todavia, quando analisados os resultados ponto a ponto, averiguou-se que a eficiência tende a 70\% para a posição de $80 \mathrm{~m}$ (Tabela 4), além de também uma tendência de comportamento mais homogêneo dos pontos experimentais ao longo do comprimento quando a concentração inicial foi aumentada. Ou seja, para menores valores de concentração de SST inicial (Co) há maior espalhamento dos pontos experimentais nas curvas que relacionam eficiência de remoção (E\%) com o comprimento.

Esses apontamentos podem ser observados na Tabela 4 e nas Figuras 7 a 11, em que são exibidos os resultados das eficiências de remoção no decorrer do comprimento do canal gramado. No tocante às Figuras 7 a 11, estão no eixo principal ainda as medições de turbidez remanescente, correspondentes aos valores das eficiências, de acordo com a Equação 3, descrita no método.

Merece ser enfatizado que, dadas a situação dinâmica e a escala de investigação, os múltiplos fatores que interferem no escoamento não

Tabela 2 - Vazões específicas $\left(q_{\mathrm{e}}\right.$ e $\left.q_{\mathrm{m}}\right)$ considerando a área molhada transversal do canal para lâminas d'água média $\left(L_{e}\right)$ e máxima $\left(L_{m}\right)$ e as vazões de descarregamento do reservatório (Qméd e Qmáx).

\begin{tabular}{|c|c|c|c|c|}
\hline$L .10^{-3}\left(\mathrm{~m}^{2}\right)$ & $\begin{array}{c}\text { Qmed.10-4 } \\
\left(\mathrm{m}^{3} \cdot \mathrm{s}^{-1}\right)\end{array}$ & $\underset{\left(\mathrm{m}^{3} \cdot \mathrm{s}^{-1}\right)}{\mathrm{Qmax} \cdot \mathrm{O}^{-4}}$ & $\begin{array}{c}\mathrm{q}_{\mathrm{e}} 10^{-2} \\
\left(\mathrm{~m}^{3} \cdot \mathrm{s}^{-1} \cdot \mathrm{m}^{-2}\right)\end{array}$ & $\begin{array}{c}\mathrm{q}_{\mathrm{m}} 10^{-2} \\
\left(\mathrm{~m}^{3} \cdot \mathrm{s}^{-1} \cdot \mathrm{m}^{-2}\right)\end{array}$ \\
\hline Médio 24 & \multirow{2}{*}{62} & \multirow{2}{*}{103} & \multirow{2}{*}{26} & \multirow{2}{*}{20} \\
\hline Máximo 52 & & & & \\
\hline
\end{tabular}

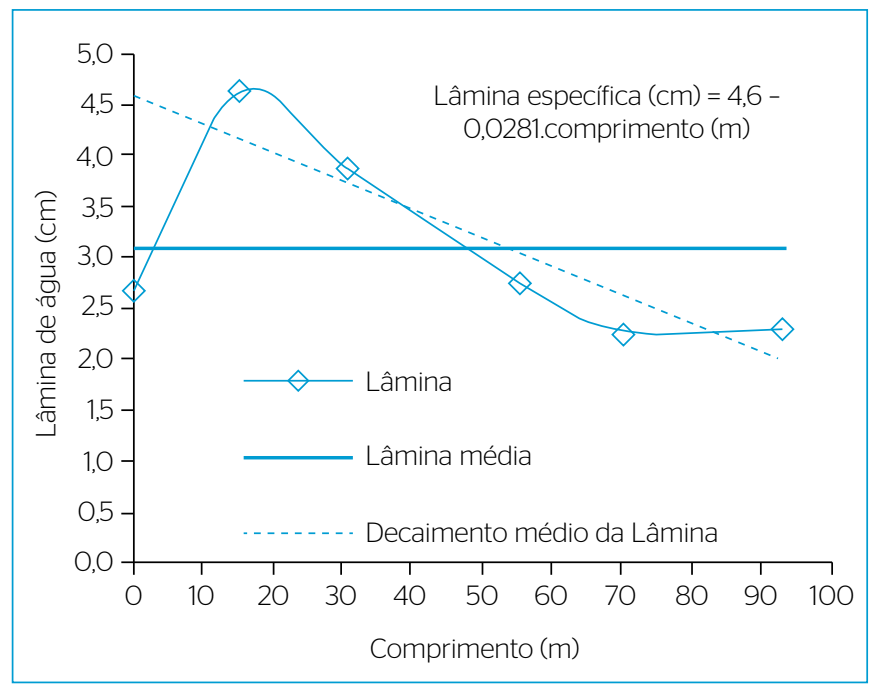

Figura 6 - Lâmina de água média, espacial e temporal, de 5 a 30 minutos medido no canal gramado. 
permanente e na remoção do material particulado refletem nos resultados experimentais. Acredita-se, por exemplo, que as eficiências de remoção de material particulado podem sofrer interferência do próprio transporte de material depositado em situação pretérita, ou mesmo do

Tabela 3 - Eficiência média dos pontos de amostragem, posicionados ao longo do comprimento do canal gramado, em função das suas respectivas concentrações iniciais em $\mathrm{mg}^{\mathrm{L}} \mathrm{L}^{-1}$.

\begin{tabular}{l|c}
$\begin{array}{l}\text { Concentração } \\
\text { inicial Co } \\
\left(m g . L^{-1}\right)\end{array}$ & $\begin{array}{c}\text { Eficiência média dos pontos de amostragem, posicionados } \\
\text { ao longo do comprimento do canal gramado } \\
(\%)\end{array}$ \\
\hline 65 & 44 \\
\hline 130 & 46 \\
\hline 196 & 35 \\
\hline 262 & 28 \\
\hline 327 & 37 \\
\hline
\end{tabular}

Tabela 4 - Eficiências medidas nos pontos de amostragem, posicionados ao longo do comprimento do canal gramado, em função das suas respectivas concentrações iniciais em $\mathrm{mg}^{\mathrm{L}^{-1}}$.

\begin{tabular}{|c|c|c|c|c|c|}
\hline \multirow{2}{*}{$\begin{array}{l}\text { Posição dos } \\
\text { coletores } \\
\text { (m) }\end{array}$} & \multicolumn{5}{|c|}{$\mathrm{Co}\left(\mathrm{mg} \cdot \mathrm{L}^{-1}\right)$} \\
\hline & 65 & 130 & 196 & 262 & 327 \\
\hline 0 & O\% & O\% & O\% & $0 \%$ & O\% \\
\hline 1 & $35 \%$ & $20 \%$ & $14 \%$ & $15 \%$ & $24 \%$ \\
\hline 2 & $23 \%$ & O\% & $8 \%$ & $17 \%$ & $25 \%$ \\
\hline 3 & $42 \%$ & $14 \%$ & $10 \%$ & $12 \%$ & $25 \%$ \\
\hline 4 & $28 \%$ & $9 \%$ & $16 \%$ & $10 \%$ & $21 \%$ \\
\hline 5 & $41 \%$ & $36 \%$ & $33 \%$ & $5 \%$ & $21 \%$ \\
\hline 6 & $50 \%$ & $14 \%$ & $25 \%$ & $10 \%$ & $19 \%$ \\
\hline 7 & $49 \%$ & $11 \%$ & $29 \%$ & О\% & O\% \\
\hline 8 & $59 \%$ & $32 \%$ & $35 \%$ & $15 \%$ & $5 \%$ \\
\hline 9 & $36 \%$ & $20 \%$ & $8 \%$ & $3 \%$ & $14 \%$ \\
\hline 10 & $54 \%$ & $32 \%$ & $16 \%$ & $8 \%$ & $17 \%$ \\
\hline 12 & $63 \%$ & $36 \%$ & $14 \%$ & $13 \%$ & $19 \%$ \\
\hline 14 & $24 \%$ & $30 \%$ & O\% & $10 \%$ & $14 \%$ \\
\hline 16 & $8 \%$ & $9 \%$ & $2 \%$ & $12 \%$ & $24 \%$ \\
\hline 18 & $25 \%$ & $36 \%$ & $35 \%$ & $12 \%$ & $21 \%$ \\
\hline 20 & $45 \%$ & $36 \%$ & $35 \%$ & $32 \%$ & $35 \%$ \\
\hline 25 & $61 \%$ & $65 \%$ & $43 \%$ & $53 \%$ & $51 \%$ \\
\hline 30 & $54 \%$ & $60 \%$ & $43 \%$ & $45 \%$ & $46 \%$ \\
\hline 35 & $48 \%$ & $50 \%$ & $37 \%$ & $22 \%$ & $37 \%$ \\
\hline 40 & $54 \%$ & $56 \%$ & $41 \%$ & $13 \%$ & $44 \%$ \\
\hline 45 & $60 \%$ & $48 \%$ & $45 \%$ & $48 \%$ & $51 \%$ \\
\hline 50 & $45 \%$ & $50 \%$ & $53 \%$ & $43 \%$ & $56 \%$ \\
\hline 60 & $40 \%$ & $27 \%$ & $57 \%$ & $53 \%$ & $63 \%$ \\
\hline 70 & $71 \%$ & $61 \%$ & $66 \%$ & $57 \%$ & $74 \%$ \\
\hline 80 & $71 \%$ & $64 \%$ & $76 \%$ & $58 \%$ & $74 \%$ \\
\hline 90 & $72 \%$ & $59 \%$ & $75 \%$ & $60 \%$ & $80 \%$ \\
\hline 100 & $100 \%$ & $100 \%$ & $100 \%$ & $100 \%$ & $100 \%$ \\
\hline
\end{tabular}

material depositado no canal gramado. Tal situação, entretanto, reflete com bastante propriedade a condição real, na qual o desempenho do sistema está sujeito.

Ainda por meio da análise das Figuras 7 a 11, pôde-se verificar tendência de decaimento exponencial das concentrações residuais remanescentes em relação ao comprimento do canal gramado. Ajustando os pontos experimentais às funções exponenciais e empregando o comprimento

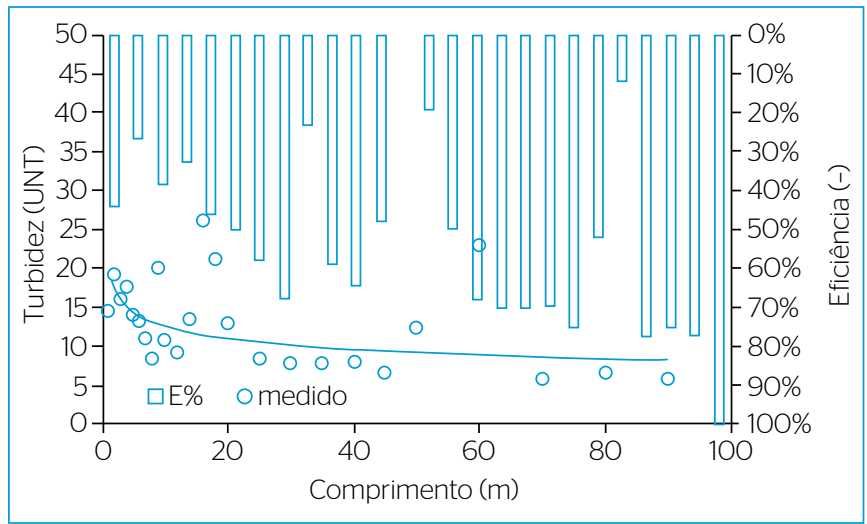

Figura 7 - Eficiência na remoção de material particulado para a concentração inicial (Co) de 65 mg SST.L-1.

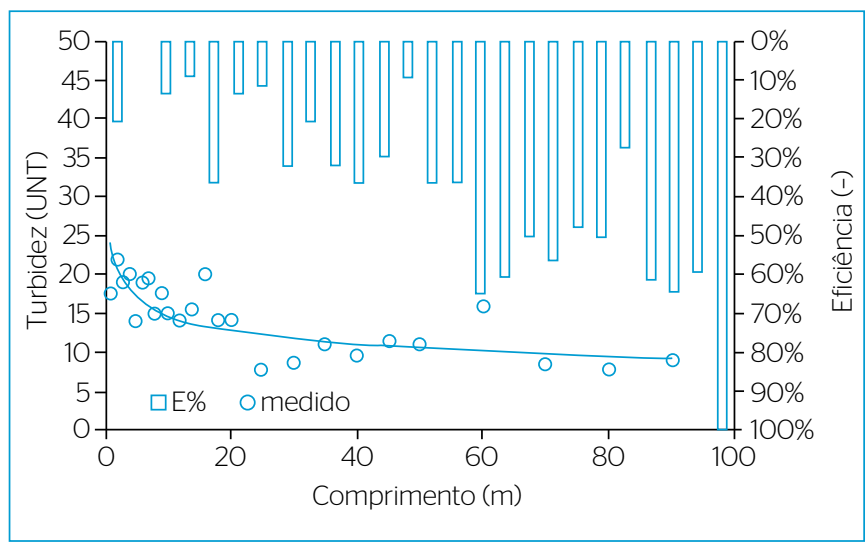

Figura 8 - Eficiência na remoção de material particulado para a concentração inicial (Co) de 130 mg SST.L-1.

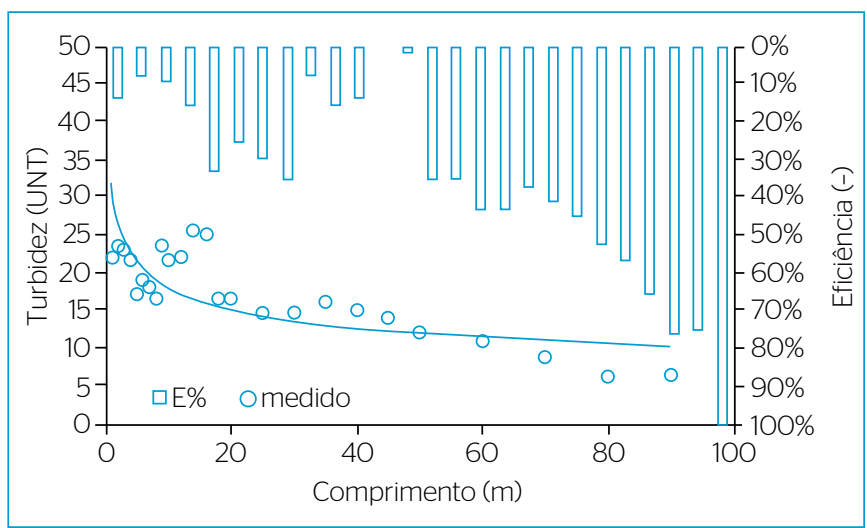

Figura 9 - Eficiência na remoção de material particulado para a concentração inicial (Co) de 196 mg SST.L-1. 
em metros como base, variável independente, e a turbidez como variável dependente, foi possível chegar aos parâmetros apresentados na Tabela 5. Ressalta-se que a avaliação da tendência apresentada buscou tão e somente uma avaliação matemática preliminar do decaimento, sem expressão fenomenológica. Todavia, a própria identificação do comportamento matemático pode auxiliar na elaboração de modelo fenomenológico em situação futura.

Os resultados de todos os ensaios realizados foram compilados em um gráfico de contorno, com linhas interpoladas de isoeficiência, tal como mostrado na Figura 12. Por meio da análise desses dados, puderam-se verificar regiões de eficiência ao longo do comprimento do canal gramado, as quais dependem da concentração inicial ( $\mathrm{Co}$ ) para serem modificadas. Embora existam pequenas regiões com descontinuidade, constatou-se que o efeito de remoção de material particulado na extensão do comprimento segue a mesma tendência para as diferentes concentrações iniciais investigadas $(\mathrm{Co})$.

Observou-se ainda que a região da vizinhança de $20 \mathrm{~m}$ de comprimento contém a maior concentração de pontos com descontinuidade na eficiência. Tal fato pode ser mais bem visualizado pela análise da Figura 13, na qual foi construída a malha que compõe a superfície da

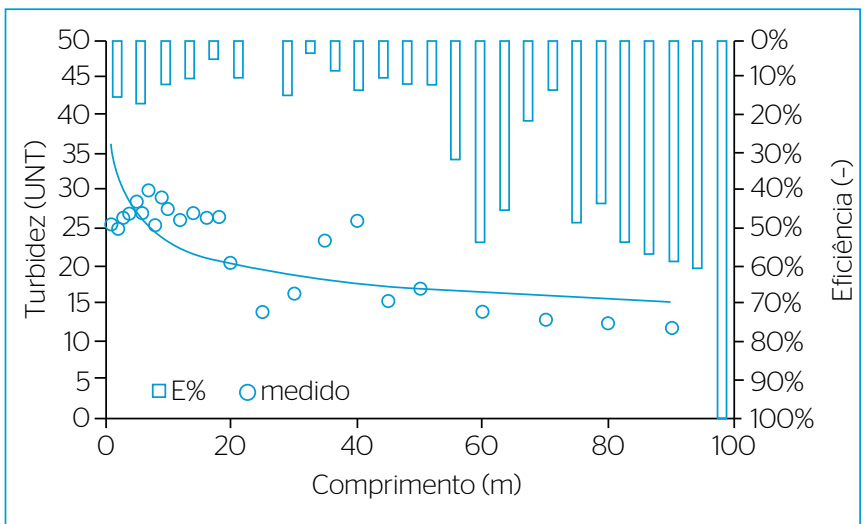

Figura 10 - Eficiência na remoção de material particulado para a concentração inicial (Co) de 262 mg SST.L-1.

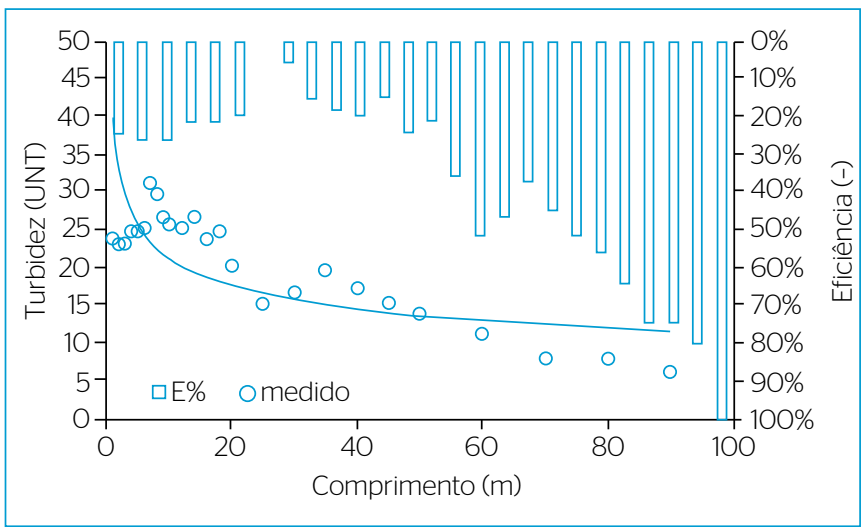

Figura 11 - Eficiência na remoção de material particulado para a concentração inicial (Co) de $327 \mathrm{mg} \mathrm{SST.L}^{-1}$ fração removida, interpolada em função do comprimento e da concentração inicial $(\mathrm{Co})$. Viu-se a existência de picos e vales, os quais podem resultar de imperfeições nas superfícies do canal gramado, de regiões de depósito em tempo pretérito e da característica dinâmica do escoamento. Entretanto, considerando que o canal gramado foi lavado antes de cada ensaio, por intermédio do descarregamento de água proveniente do reservatório, e que a superfície do canal não apresenta imperfeições que possam ser detectadas por meio de uma inspeção de campo, inferiu-se que a passagem da onda de cheia foi a principal responsável pela descontinuidade confirmada em todos os ensaios realizados.

Tabela 5 - Parâmetros do ajuste do decaimento exponencial para diferentes valores de concentração inicial $(\mathrm{Co})$ no canal gramado.

\begin{tabular}{l|c|c|c}
$\begin{array}{l}\text { Concentração inicial - } \\
\text { Co }\left(\mathrm{mg}^{-1} \mathbf{L}^{-1}\right.\end{array}$ & $\begin{array}{c}\text { Termo multiplicativo } \\
\text { da base (NTU) }\end{array}$ & $\begin{array}{c}\text { Expoente } \\
\left(\mathrm{m}^{-1}\right)\end{array}$ & $\mathbf{R}^{2}$ \\
\hline 65 & 19,70 & $-0,13$ & 0,27 \\
\hline 130 & 23,92 & $-0,21$ & 0,59 \\
\hline 196 & 31,77 & $-0,25$ & 0,59 \\
\hline 262 & 36,24 & $-0,19$ & 0,57 \\
\hline 327 & 40,16 & $-0,27$ & 0,58 \\
\hline
\end{tabular}

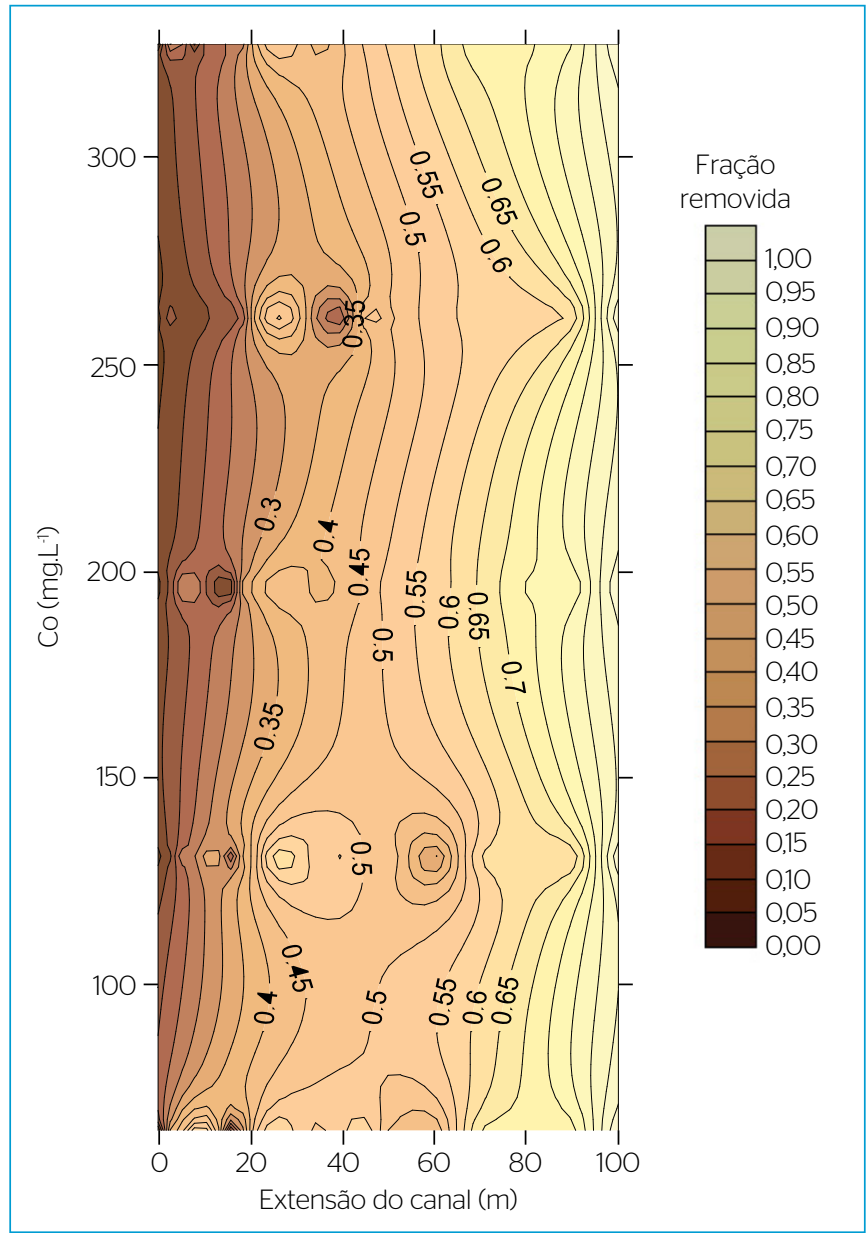

Figura 12 - Fração removida de sólidos suspensos totais (SST) ao longo do comprimento do canal gramado para diferentes valores de concentração inicial. 
O gráfico da Figura 14 foi construído por meio da combinação da malha interpolada, apresentada na Figura 13, com a variação do nível durante a passagem da onda de cheia, exposta na Figura 6. Pode-se notar que existe uma coincidência entre o ponto de máxima lâmina d'água detectada no canal gramado e as posições em que foram observadas descontinuidades, as quais são visualizadas pela presença de picos e vales na superfície do gráfico. Acredita-se que essas descontinuidades sejam atribuídas aos campos de velocidade local, os quais variam também com a passagem da onda de cheia pelo canal gramado na posição em torno de 15 a $20 \%$ do comprimento.

O canal gramado deve ser visto como parte integrante de um conjunto mais amplo de técnicas de baixo impacto, em que é possível que

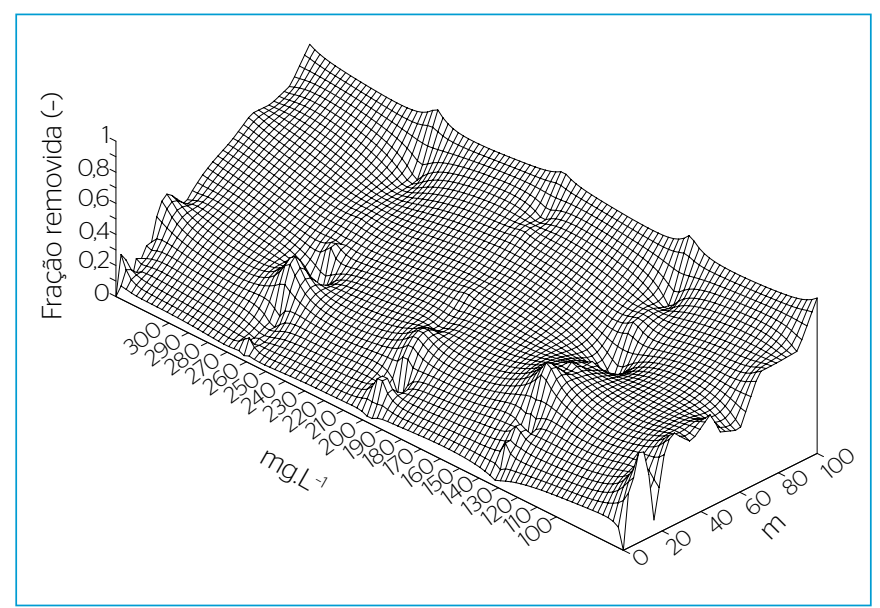

Figura 13 - Fração removida de sólidos suspensos totais (SST) no canal gramado em função da concentração inicial $(\mathrm{Co})$ e do comprimento.

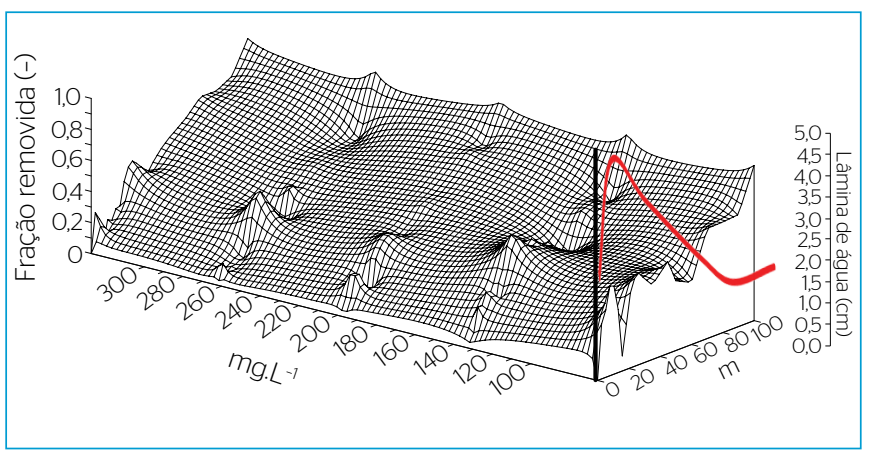

Figura 14 - Fração removida de SST no canal gramado em função da concentração inicial ( $\mathrm{Co}$ ), do comprimento e da lâmina d'água média medida durante a passagem da onda de cheia. o efeito do conjunto propicie melhorias significativas no desempenho da drenagem urbana, no que tange à qualidade e à quantidade de águas pluviais escoadas em superfície.

Nesse sentido, este trabalho lança uma pequena luz sobre o desempenho desse dispositivo, e trabalhos futuros são necessários visando ao aprofundamento das questões levantadas.

\section{CONCLUSÕES}

Com base nos resultados obtidos nos ensaios com o canal gramado construído em escala real, pôde-se concluir:

- a remoção de material particulado é dependente da concentração inicial $(\mathrm{Co})$ presente no afluente e da extensão no canal. A remoção de cerca de 50\% do material particulado ocorreu para distâncias de até $50 \mathrm{~m}$ para todas as concentrações iniciais investigadas. Para a posição de $80 \mathrm{~m}$, verificaram-se remoções da ordem de $70 \%$;

- para a menor concentração inicial investigada $\left(65 \mathrm{mg} . \mathrm{L}^{-1}\right)$, verificaram-se maior dispersão dos dados experimentais e vice-versa;

- a remoção apresenta comportamento matemático com tendência de decaimento exponencial em relação ao comprimento. Tal comportamento pode auxiliar na compreensão fenomenológica da remoção em trabalhos futuros;

- a passagem da onda de cheia, com pico detectado na posição em torno de 15 a $20 \%$ do comprimento total do canal, pode ser responsável pela variação de eficiência detectada em todos os ensaios realizados.

O uso de canal gramado apresenta-se como opção viável para melhoria da qualidade da água do ESD, além de outros benefícios com aumento do tempo de concentração, contribuição para infiltração e, provavelmente, redução de custos.

\section{AGRADECIMENTOS}

Os autores agradecem à Financiadora de Estudos e Projetos (FINEP) pelos recursos empregados nesta pesquisa, referente ao Projeto do Ministério da Ciência, Tecnologia e Inovação (MCTI)/FINEP/Ação Transversal Saneamento Ambiental e Habitação 07/2009 Manejo de Águas Pluviais Urbanas 2 (MAPLU2).

\section{REFERÊNCIAS}

APHA. American Public Health Association. (2005). Standard methods: for the examination water \& wastewater. 21 ed. Washington: Centennial Edition.
BAPTISTA, M.; NASCIMENTO, N.; BARRAUD, S. (2011). Técnicas compensatórias em drenagem urbana. 2 ed. Porto Alegre: ABRH. 318p. 
BLICK, S. A.; KELLY, F.; SKUPIEN, J. J. (2004). New Jersey Stormwater Best Management Practices Manual. Nova Jersey: Division of Watershed Management.

CAMPBELL, N.; D’ARCY, B.; FROST, A.; NOVOTNY, V.; SANSOM, A. (2004). Diffuse pollution: an introduction to the problems and solutions. Londres: IWA Publishing. 310p.

EPA. Environmental Protection Agency. (1999). Nationwide urban runoff program. Washington.

GEORGE'S COUNTY. (1999). Low-impact development design strategies: an integrated design approach. Prince George's: Department of Environmental Resource. Programs and Planning Division. 150p.

GHARABAGHI, B.; RUDRA, R.; WHITELEY, H.; DICKINSON, W. (2000). Sediment-removal efficiency of vegetative filter strips. Ontário, Canadá: School of Engineering, University of Guelph.

GUTIERREZ, L. A. R. (2011). Avaliação da qualidade da água da chuva de um sistema filtro-vala-trincheira de infiltração no tratamento do escoamento superficial direto predial em escala real em São Carlos - SP. 198p. Dissertação (Mestrado em Engenharia Urbana)Universidade Federal de São Carlos, São Carlos.

HUMBEL, X.; LAZZAROTTO, P.; VIAU, J. Y. (2004). Méthodologie de choix et de dimensionnement de techniques innovantes de traitement dês rejets par temps de pluieaufil de l'eau. In: INTERNATIONAL CONFERENCE ON SUSTAINABLE TECHNIQUES AND STRATEGIES IN URBAN WATER MANAGEMENT, GRAIE AND INSA, 5., Lyon, France. Proceedings... Lyon, France: Novatech.

LI, J. \& PYATT, L. (2004). Performance evaluation of a stormwater quality pond during construction stages. In: INTERNATIONAL
CONFERENCE ON SUSTAINABLE TECHNIQUES AND STRATEGIES IN URBAN WATER MANAGEMENT, GRAIE AND INSA, 5., Lyon, France. Proceedings... Lyon, France: Novatech.

Lima, J. L. P.; Abrantes, J. R. C. B. (2014). Using a thermal tracer to estimate overland and rill flow velocities. Earth Surface, Processes and Landforms, 39, p. 1293-1300. DOI: 10.1002/esp.3523

PARKINSON, J. \& MARK, O. (2008). Urban stormwater management in development countries. Londres: IWA.

PERSON, J.; SOMES, N.; WONG, T. (1999). Hydraulics efficiency of constructed wetlands and ponds. Water Science and Technology, v. 40, n. 3, p. 291-300. DOI: 10.1016/SO273-1223(99)00448-5

PORTO, M. F. A. (1995). Aspectos qualitativos do escoamento superficial em áreas urbanas. In: TUCCl, C. E. M.; PORTO, R. L.; BARROS, M. T. (Eds.). Drenagem urbana. Porto Alegre: ABRH/ Editora da UFRGS. p. 387-428.

SILVA, A.; VIEIRA, L.; NASCIMENTO, N. O. (2009). Caracterização do escoamento urbano de origem viária e remoção de seus poluentes por meio de técnicas compensatórias. In: SIMPÓSIO BRASILEIRO DE RECURSOS HIIDRICOS, 18., Campo Grande, 2009. Anais... Porto Alegre: ABRH.

SILVEIRA, A. (2002). Drenagem urbana: aspectos de gestão Instituto de Pesquisas Hidráulicas, Universidade Federal do Rio Grande do Sul. Porto Alegre: IPH/UFRGS.

TUCCI, C. (2005). Gestão de águas pluviais urbanas. Brasília: Ministério das Cidades; Global Water Partnership; Wolrd Bank; Unesco.

URBONAS, B. \& STAHRE, P. (1993). Stormwater best management practices and detention. Nova Jersey: Prentice Hall, Englewood Cliffs 